
CHRONIC NON-BACTERIAL OSTEOMYELITIS

\section{AB1067 THE IMPACT OF ACUTE RHEUMATIC FEVER IN A PROVINCE OF CENTRAL-NORTH ITALY}

Elena Tronconi ${ }^{1}$, Erika Miglionico ${ }^{1}$, Andrea Donti ${ }^{2}$, Andrea Pession ${ }^{1}$, Angela Miniaci'. ' Sant'Orsola-Malpighi Hospital, University of Bologna, Department of Pediatrics, Bologna, Italy, ${ }^{2}$ Sant'Orsola-Malpighi Hospital, Pediatric Cardiology and Adult Congenital Heart Disease Program, Bologna, Italy

Background: Acute rheumatic fever (ARF) is a multisystem complication of group A streptococcal (GAS) infection. The incidence of ARF varies greatly in different geographic areas, with the highest incidence in Asia, Eastern Europe, and Australia (10-350 out of 100000 per year) (1) and lowest (0.5-3 out of 100 000) in the US and Western Europe.

In 2015 the latest version of Jones Criteria has been published (2), incidence less than 2 out of 100.000 per year was established to define low-risk (LR) population. Due to the lack of nationwide epidemiologic data in Italy, it is difficult to define the correct population Jones criteria's category to use.

Objectives: To estimate the incidence of ARF in a metropolitan area of Central-North Italy and to study the clinical characteristics of the disease in a developed country.

Methods: We retrospectively analyzed the data of all patients with ARF aged 5-14 years old, diagnosed according to the classical and now LR Jones criteria (2), referred to Sant'Orsola-Malpighi Hospital of Bologna from January 2012 to December 2017 living in the province of Bologna. Results: We identified a total of 24 patients diagnosed by ARF. In the province of Bologna, the inhabitants between 5 and 14 years of age varied from 82.967 in 2012 to 89.699 in 2017. Every year the annual incidence of ARF was above 2 out of 100.000 . The highest incidence was reported in 2013 with 8 new diagnosis (incidence of 9.3 out of 100000 per year). Carditis was present in 20 patients (83.3\% of cases), chorea in 8 children $(33.3 \%)$. Only 3 patients presented polyarthritis at diagnosis while 9 had polyartralgia and 3 presented with monoarthritis. In 6 patients the diagnosis followed the onset of chorea and no joint involvement was recorded. In 5 patients the diagnosis of ARF was made after the detection of classical cardiac findings without other major criteria. Cardiac involvement was characterized by mitral regurgitation in 17 cases and aortic regurgitation in 10 (8 patients with mitral aortic involvement). Five patients presented with fever $\left(\geq 38.5^{\circ} \mathrm{C}\right)$, 11 children had elevated inflammatory markers as erythrocyte sedimentation rate (ESR) $\geq 60 \mathrm{~mm} / \mathrm{h}$ and/ or C-reactive protein (CRP) $\geq 3.0 \mathrm{mg} / \mathrm{dL}$. Only 5 patients had positive swab for GAS. Twelve patients $(50 \%)$ were treated with steroid. Fourteen patients received secondary prophylaxis every 28 days, two of them switched to every 21 days.

Conclusion: Our study confirms the previous published data of Breda et al. (3) and Licciardi et al. (4) in other Italian areas supporting the evidence for high risk (HR) in our region. Furthermore, this study shows that in our population only few patients had the classical polyarthritis presentation. It is important to consider the new HR criteria for arthritis in order not to miss diagnosis. A careful clinical history is needed because the demonstration of GAS infection is often difficult. These data may strengthen the hypothesis to consider our whole country as a HR area for ARF. A nationwide study is mandatory.

\section{REFERENCES}

[1] Carapetis J, McDonald M, Wilson N. Acute rheumatic fever. Lancet 2005:366:155-68.

[2] Gewitz H, Baltimore R, Lloyd T, Craig S, Stanford S, Carapetis J. Revision of the Jones Criteria for the diagnosis of acute rheumatic fever in the era of Doppler echocardiography: a scientific statement from the American Heart Association. Circulation 2015:131:1806-18.

[3] Breda L, Marzetti V, Gaspari S, Del Torto M, Chiarelli F, Altobelli E. Population-based study of incidence and clinical characteristics of rheumatic fever in Abruzzo, central Italy, 2000-2009. J Pediatr. 2012 May;160(5):8326.e1.

[4] Licciardi F, Scaioli G, Mulatero R, Marolda A, Delle Piane M, Martino S, Montin D, Tovo PA. Epidemiologic Impact of the New Guidelines for the Diagnosis of Acute Rheumatic Fever. J Pediatr. 2018 Jul;198:25-28.e1.

Disclosure of Interests: None declared

DOI: 10.1136/annrheumdis-2019-eular.7737
Ceyhun Acarı ${ }^{1}$, Elif Çomak ${ }^{2}$, Şükrü Çekiç̧ ${ }^{3}$, Serkan Turkucar ${ }^{1}$, Hatice Adiguzel Dundar', Sara Şebnem Kılıç ${ }^{3}$, Sema Akman ${ }^{2}$, Erbil Unsall ${ }^{1} .{ }^{1}$ Dokuz Eylül University Faculty of Medicine, Department of Pediatri, Balcova, Turkey, ${ }^{2}$ Akdeniz University Faculty of Medicine, Department of Pediatri, Antalya, Turkey, ${ }^{3}$ Uludağ University Faculy of Medicine, Department of Pediatri, Bursa, Turkey

Background: Chronic non-bacterial osteomyelitis (CNO) is a rare bone disease of autoinflammatory origin. CNO patients present with bone, joint pain and swelling. Other autoinflammatory disorders such as palmoplantar pustulosis, psoriasis and inflammatory bowel disease may accompany CNO.

Objectives: Our aim is to determine demographic, clinical and radiological characteristics of Turkish children with CNO.

Methods: Clinical, laboratory features and imaging findings were retrospectively analyzed in 28 CNO Turkish patients from three pediatric rheumatology centers. Clinical findings, radiological data, treatments and outcome were evaluated.

Results: Of the 28 CNO patients, 10 (35.7\%) female and 18 (64.3\%) were male. Mean age at diagnosis was 9.54 (3-16.5) year. The lag time between symptoms and diagnosis was $6.5(0-60)$ months. The median follow-up time was $18.5(1-107)$ months. At the time of admission, symptoms were arthralgia $(75.0 \%)$, bone pain $(64.3 \%)$, limping $(32.1 \%)$, swelling $(28.6 \%)$, weakness $(10.7 \%)$, and fever (3.6\%). Two patients had inflammatory bowel disease (IBD) and six had familial Mediterranean fever (FMF). The bone lesions were mostly multifocal (\%96.4),\%3.6 was unifocal. The most frequently involved bones were femur $(67.9 \%)$, tibia $(53.6 \%)$ and pelvic bones (32.2\%). (Table I) The patients had mildly elevated CRP and ESH levels. HLA B27 association was 25\%. ANA was positive in $5 \%$. All patients were RF negative. Six patients had mutations in the MEFV gene, all of them had M694V allele. The most common finding in Histopathological examination $(n=9)$ demonstrated sterile mixed cell infiltration composed of lymphocyte and neutrophils. MRI results were mostly defined as bone marrow edema, and bone scan findings showed increased osteoblastic activity. All of patients received NSAIDs. Other drugs were methotrexate $(46.4 \%)$ sulfasalazine $(39 \%)$, steroids $(25 \%)$, anti-TNF drugs $(32 \%)$, and pamidronate $(25 \%)$. Response to treatment was partial in $32.1 \%$, whereas $39.3 \%$ patients had complete remission There was no response in 8 patients $(28.6 \%)$

Conclusion: CNO was first described by Giedion in 1972 as multifocal bone lesions of inflammatory origin. ${ }^{1}$ There are 500 CNO patients reported in the literature as individual or case series. ${ }^{2}$ The laboratory findings are nonspecific and the diagnosis is mostly clinical and radiological. MRI and bone scan are the most commonly used imaging modalities. Histopathological results are non-specific, and may be necessary to exclude infection and malignancy. NSAIDs, sulfasalazine and methotrexate are mostly used in the treatment. Steroids, biological drugs and pamidronate are other options. There is still need for further treatment options, because there are significant number of resistant patients.

\section{REFERENCES}

[1] - Taddio A, Ferrara G, Insalaco A, Pardeo M, Gregori M, Finetti M, Pastore S, Tommasini A, Ventura A, Gattorno M. Dealing with Chronic Non-Bacterial Osteomyelitis: a practical approach Pediatric Rheumatology (2017) 15:87

[2] - Marion R. Roderick, Ethan S. Sen and Athimalaipet V. Ramanan Chronic recurrent multifocal osteomyelitis in children and adults: current understanding and areas for development Rheumatology, Volume 57, Issue 1, 1 January 2018, Pages 41-48 doi:10.1093/rheumatology/kex066

\begin{tabular}{lcc}
\hline Affected bones & $\boldsymbol{n}$ & $\%$ \\
\hline Femur & 19 & 67.9 \\
Tibia & 15 & 53.6 \\
Pelvic bones & 9 & 32.1 \\
Calcaneus-talus & 6 & 21.4 \\
Clavicula & 4 & 14.3 \\
Mandible & 3 & 10.7 \\
Vertebra & 2 & 7.1 \\
Metatars & 2 & 7.1 \\
Sacrum & 1 & 3.6 \\
Cranium & 1 & 3.6 \\
Localisation & $n$ & $\%$ \\
Metaphysis & 17 & 60.7 \\
Metaphysis- & 6 & 21.4 \\
epiphysis & & \\
Metaphysis- & 4 & 14.3 \\
diaphysis & & 3.6 \\
Diaphysis & 1 & \\
\hline
\end{tabular}

